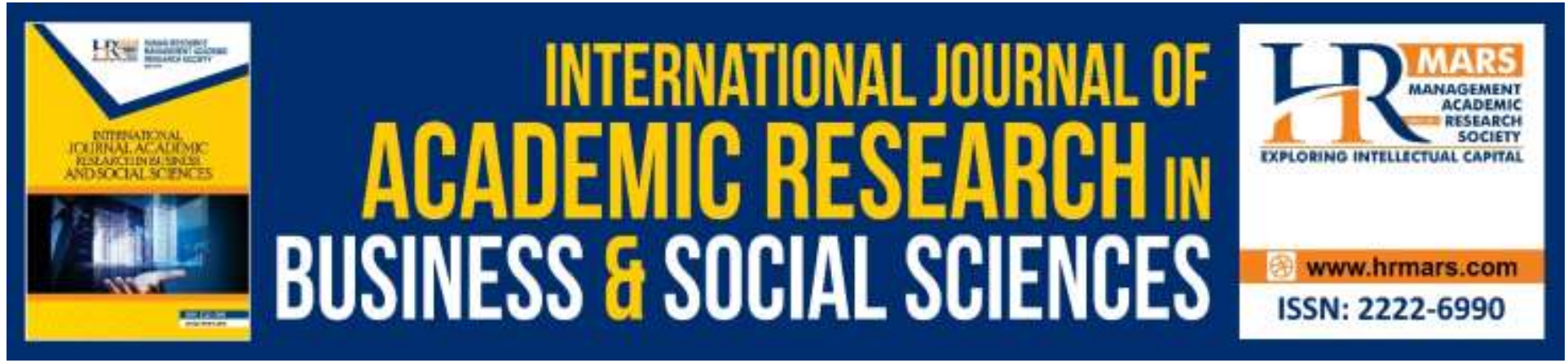

\title{
Application Encouragement of Emotional Intelligence Module as a Strategy for Strengthening the Development of Emotional Intelligence College Student Council
}

Syed Sofian Syed Salim, Md Amin Md Taff, Mohd Hanafi Mohd Yasin, \& Badaruddin Ibrahim

To Link this Article: http://dx.doi.org/10.6007/IJARBSS/v9-i9/6329

DOI: $10.6007 /$ IJARBSS/v9-i9/6329

Received: 22 July 2019, Revised: 19 August 2019, Accepted: 01 September 2019

Published Online: 29 September 2019

In-Text Citation:(Salim, Taff, Yasin, \& Ibrahim, 2019)

To Cite this Article: Salim, S. S. S., Taff, M. A. M., Yasin, M. H. M., \& Ibrahim, B. (2019). Application Encouragement of Emotional Intelligence Module as A Strategy For Strengthening the Development of Emotional Intelligence College Student Council. International Journal of Academic Research in Business and Social Sciences, 9(9), 557-566.

Copyright: (c) 2019 The Author(s)

Published by Human Resource Management Academic Research Society (www.hrmars.com) This article is published under the Creative Commons Attribution (CC BY 4.0) license. Anyone may reproduce, distribute, translate and create derivative works of this article (for both commercial and non-commercial purposes), subject to full attribution to the original publication and authors. The full terms of this license may be seen at: http://creativecommons.org/licences/by/4.0/legalcode

Vol. 9, No. 9, 2019, Pg. 557 - 566

http://hrmars.com/index.php/pages/detail/IJARBSS

JOURNAL HOMEPAGE

Full Terms \& Conditions of access and use can be found athttp://hrmars.com/index.php/pages/detail/publication-ethics 


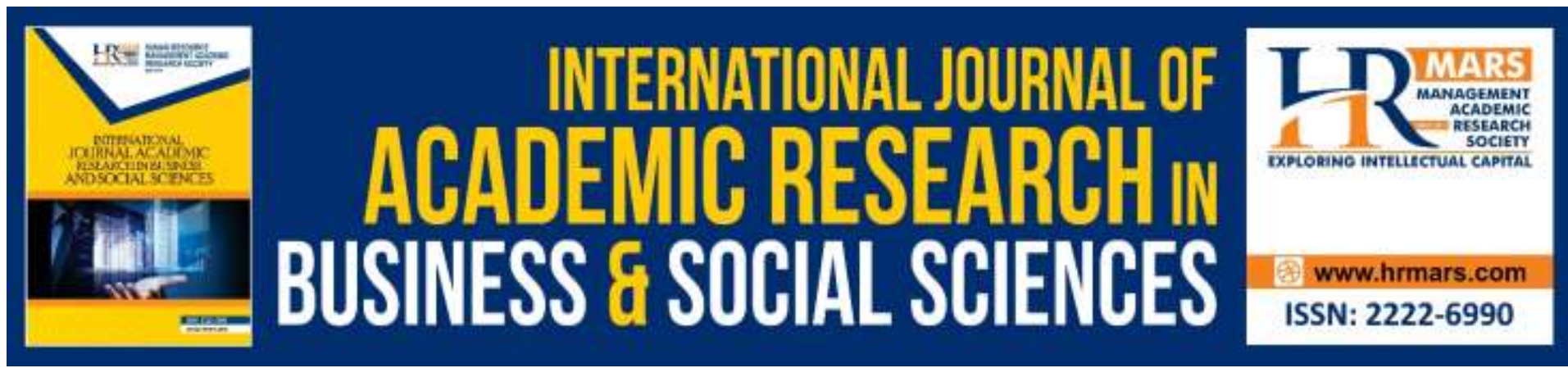

\title{
Application Encouragement of Emotional Intelligence Module as A Strategy For Strengthening the Development of Emotional Intelligence College Student Council
}

\author{
Syed Sofian Syed Salim ${ }^{1}$, Md Amin Md Taff ${ }^{2}$ \\ Mohd Hanafi Mohd Yasin ${ }^{3}$, \& Badaruddin Ibrahim ${ }^{4}$ \\ ${ }^{1}$ Faculty of Education and Human Development, Sultan Idris Education University, 35900 \\ Tanjong Malim, Perak, Malaysia, ${ }^{2}$ Faculty of Sports Science and Coaching, Sultan Idris \\ Education University, 35900 ,Tanjong Malim, Perak, Malaysia, ${ }^{3}$ Faculty of Education, \\ National University of Malaysia, 43600 Bangi, Selangor, Malaysia, ${ }^{4}$ Faculty of Technical and \\ Vocational Education, Tun Hussein Onn University, 86400 Batu Pahat, Johor, Malaysia
}

\section{Abstract}

The study aims to measure the level of Emotional Intelligence (EI) on the College Student Council (CSC) Sultan Idris Education University (UPSI). Sample selection was conducted with a total of 180 members of the CSC consisting of 6 colleges namely Aminuddin Baki College (KAB), Za'aba College (KZ), Harun Aminurrashid College (KHAR), Ungku Omar College (KUO), Awang Had Salleh College (KAHS) and Campus Offshore Unit (UKLK) as respondents. This study uses survey and quasi-experimental methods. The research instrument is a set of questionnaire which consists of two sections, Part A on respondents' demographics and part $B$ on Sofian Emotional Intelligence Inventory (SofiElI). Whereas for quasi-experiments using the application Encouragement of Emotional Intelligence Module (EeiM). The data obtained were analyzed using descriptive statistics, percentage, frequency, and mean. The findings show that there is no difference between sex between moderate and high levels, while for high levels there is a difference in CSC members. The findings also show that there is a difference between the sexes between medium to high level and high level CSC members for dimension of self-emotion, self-management dimension, dimension of social efficiency and dimensions of social skills. Findings after the intervention found that there was a difference between the sexes and the increase to the high level of CSC members. The findings of the post-intervention study on the dimensions of self-emotion, the selfmanagement dimension and social efficiency found that there was a difference between sex between medium to high and high levels, finding also showed a high elevation of El for each dimension. For the dimensions of social skills, there is no difference between sex between moderate and high levels, but for high levels there is a difference between sexes, finding also show a high level of improvement for dimensions of social skills. In conclusion, gender 
factors can make a difference to the level of El and the difference of each dimension before and after the intervention.

Keywords: Emotional Intelligence, College Student Council, Sofian Emotional Intelligence Inventory, Support Emotional Intelligence Module

\section{Introduction}

According to Goleman (1995) Emotional Intelligence (EI) is the ability to control the emotions of others and the emotions of others, to distinguish the good and to use one's thoughts and actions. El is also the ability of a person to understand his own feelings and use them to make the right decision in everyday life. Individuals with high El are more able to control their disappointment, sadness and negative feelings. If the individual is facing difficulties, El can help him to continue to be motivated and optimistic to achieve the goals set.

During this time El was underestimated and deserted by researchers. Researchers, even including parents, only view El as a very important and highly respected aspect. Therefore they are trying to improve the ability of their children. In fact, parents are sending their children in various motivational courses for the enhancement of their children's IQ so that the El and spiritual Intelligence (SI) are ignored.

El plays a role in personal development and can only be achieved through the individual role itself in enhancing his ability to know his emotions, managing his own emotions and self-motivating ability. Additionally, individuals with high El have the ability to recognize other individual emotions in the vicinity, especially in the lecture and college room environment, as well as to build and create good communication and harmonious communication at all levels. El also plays a role in developing characters that can be achieved through individual roles in enhancing their ability to recognize emotions, selfmanagement, social competencies and social skills.

Niehoff \& Moorman (1993) states that behavioral characteristics in organizational citizenship are prosocial behavior which can bring good to oneself and the relationship between these variables can help in looking at the level of El College Student Council (CSC) members.

\section{Methodology}

The study involved members of CSC from 6 colleges namely Aminuddin Baki College (KAB), Za'aba College (KZ), Harun Aminurrashid College (KHAR), Ungku Omar College (KUO), Awang Had Salleh College (KAHS) and Campus Offshore Unit (UKLK) which is a college-level student leader. The study involved a total of 180 CSC members comprising all levels of gender, age, race and religion. The sampling method used is purposive sampling.

A set of questionnaires was used which contained two sections: A, demographic factors, while part B, using the Sofian Emotional Intelligence Inventory questionnaire (SofiEII) built by Syed et al (2016). This questionnaire was used for the purpose of studying El among CCC members. SofiEll contains 80 items represented by four sub-scales. Each sub-scale contains 20 items which all represent 15 positive items and 5 negative items based on the sub-scale being constructed. Whereas for quasi-experiments using the Encouragement of Emotional Intelligence Module (EeiM).

The data obtained were analyzed using descriptive statistics, percentage, frequency, and mean. Scoring section B is a questionnaire on El contains 80 items in likert form. Each item 
in this section uses a 4-point likert scale response format from "highly disagreeable" to "very agreeable". For the purpose of simplifying the analysis, scoring is divided into two, ie Interpretation based on Sub-Scale and Interpretation based on SofiEll overall Score.

Table 1: Score and consent to the Disclosure Items part B (EI)

\begin{tabular}{cc}
\hline Skor & Consent To The Disclosure Items \\
\hline 1 & Strongly Disagree \\
2 & Do Not Agree \\
3 & Agree \\
4 & Strongly Agree \\
\hline
\end{tabular}

Table 2: Interpretation based on the level of Sub-Scale based on the dimensions of SofiEll

\begin{tabular}{cc}
\hline Sub Scale & Scoring \\
\hline High & $61-80$ \\
Medium High & $41-60$ \\
Medium Low & $21-40$ \\
Low & $1-20$ \\
\hline
\end{tabular}

Table 3: Interpretation based on the level of the overall score SofiEll

\begin{tabular}{cc}
\hline Sub Scale & Scoring \\
\hline High & $241-320$ \\
Medium High & $161-240$ \\
Medium Low & $81-160$ \\
Low & $1-80$ \\
\hline
\end{tabular}

\section{Result}

The following is the result of the descriptive analysis of the respondent's study which included the gender demographics.

Table 4: Gender Analysis of Respondents

\begin{tabular}{ccc}
\hline Gander & Frequency & Percentage \\
\hline Men & 82 & $45.6 \%$ \\
Women & 98 & $54.4 \%$ \\
\hline Jumlah & $\mathbf{1 8 0}$ & $\mathbf{1 0 0 . 0 \%}$ \\
\hline
\end{tabular}

Based on table 4, the number of respondents is 180 people. A total of 82 were men (45.6\%) while 98 were women CSC members (54.4\%). This shows that the number of women CSC member respondents exceeded the number of men CSC member respondents.

Table 5: Emotion Policy Level Analysis (EI) College Student Council Members (CSC)

\begin{tabular}{lcccc}
\hline $\begin{array}{l}\text { The Level Of Emotional } \\
\text { Intelligence }\end{array}$ & Men & Women & Min & S.P \\
\hline Medium High & $14.4 \%$ & $14.4 \%$ & 3.7111 & .45451 \\
High & $31.1 \%$ & $40.0 \%$ & & \\
\hline
\end{tabular}


Table 5 shows an analysis of the level of emotional intelligence $(\mathrm{min}=3.7111, \mathrm{~S} . \mathrm{P}=.45451)$ by gender. The findings showed that there were no differences between men and women at $14.4 \%$ (26 persons). Meanwhile, for high levels, $40.0 \%$ (72) women were followed by men as much as $31.1 \%$ (56 persons).

Table 6: An Analysis of the level of Emotional Intelligence (EI) College Student Council (CSC) in the dimensions of Emotional Identification.

\begin{tabular}{lcccc}
\hline $\begin{array}{l}\text { Dimension of Emotional } \\
\text { Identification }\end{array}$ & Men & Women & Min & S.P \\
\hline Moderate High & $8.3 \%$ & $12.2 \%$ & 3.7944 & .40523 \\
High & $37.2 \%$ & $42.2 \%$ & & \\
\hline
\end{tabular}

Table 6 shows an analysis of emotional level dimensions (Min $=3.7944$, S.P $=.40523$ ) by gender. The findings show that there are differences in gender to moderate and high levels. Highly moderate levels for women were $12.2 \%$ (22 persons) followed by men $8.3 \%$ (15 people). While the high level showed women as much as $42.2 \%$ (76 persons) followed by men as much as $37.2 \%$ (67 persons).

Table 6: analysis of the level of Emotional Intelligence (EI) College Student Council (CSC) in dimensions of Emotional Identification.

\begin{tabular}{lcccc}
\hline $\begin{array}{l}\text { Dimensions of Emotional } \\
\text { Identification }\end{array}$ & Men & Women & Min & S.P \\
\hline Medium High & $20.6 \%$ & $26.1 \%$ & 3.5333 & .50028 \\
High & $25.0 \%$ & $28.3 \%$ & & \\
\hline
\end{tabular}

Table 7 shows an analysis of dimension of self-management dimension ( $\mathrm{Min}=3.5333$, S.P $=$ .50028 ) by sex. The findings show that there are differences in medium and high levels of gender. The moderate level for women was $26.1 \%$ (47 persons) followed by men at $20.6 \%$ (37 persons). For high levels, $28.3 \%$ (51 persons) and $25.0 \%$ (45 persons) were women.

Table 8: Analysis of the level of Emotional Intelligence (EI) College Student Council (CSC) The dimensions of Social Efficiency

\begin{tabular}{lcccc}
\hline Dimensi of Social Effiency & Men & Women & Min & S.P \\
\hline Medium HIgh & $16.1 \%$ & $15.6 \%$ & 3.6833 & .46647 \\
High & $29.4 \%$ & $38.9 \%$ & & \\
\hline
\end{tabular}

Table 8 shows an analysis of the level of social efficiency dimension (Min $=3.6833$, S.P $=$ .46647) by gender. The findings showed the difference between medium and high levels of gender. The average high level for men was $16.1 \%$ (29 people) followed by $15.6 \%$ (28 women). While high levels showed $38.9 \%$ (70) and $29.4 \%$ (53) mens. 
Table 9: Emotional Intelligence Level Analysis (EI) College Student Council (CSC) in the dimensions of social skills

\begin{tabular}{lcccc}
\hline Dimension of Social Skills & Men & Women & Min & S.P \\
\hline Medium High & $23.9 \%$ & $26.1 \%$ & 3.5000 & .50139 \\
High & $21.7 \%$ & $28.3 \%$ & & \\
\hline
\end{tabular}

Table 9 shows the analysis of dimension of social skills (Min $=3.5000$, S.P $=.50139$ ) by gender. The findings show that there are differences in sex between medium and high levels. The moderate level for women was $26.1 \%$ ( 47 persons) followed by men at $23.9 \%$ ( 43 persons). While high levels showed 28.3\% (51) and men (21.7\%) (39 persons).

Table 10: An Analysis of Level of Emotional Intelligence (EI) College Student Council Members (CSC)

\begin{tabular}{lcccc}
\hline $\begin{array}{l}\text { Level of Emotional } \\
\text { Intelligence }\end{array}$ & Men & Women & Min & S.P \\
\hline High & $45.6 \%$ & $54.4 \%$ & 4.0000 & .00000 \\
\hline
\end{tabular}

Table 10 shows the analysis of emotional intelligence ( $m e a n=4.0000, \mathrm{~s} . \mathrm{P}=.00000$ ) by gender. The finding shows that there are differences in the level of high level by gender i.e. women of $54.4 \%$ ( 98 people) followed by men of $45.6 \%$ ( 82 people).

Table 11: Analysis of the level of Emotional Intelligence (EI) College Student Council (CSC) The dimensions of Emotional Identification

\begin{tabular}{lllll}
\hline $\begin{array}{l}\text { Dimension of Emotional } \\
\text { Indentification }\end{array}$ & Men & Women & Min & S.P \\
\hline Medium High & $1.7 \%$ & $0.6 \%$ & 3.9778 & .14782 \\
High & $43.9 \%$ & $53.9 \%$ & & \\
\hline
\end{tabular}

Table 11 shows the analysis for identification of emotional dimension (mean $=3.9778$, s. $\mathrm{P}=$. 14782) according to group sex. The finding shows that there are differences in the level for high and medium level high by gender. A moderate level of men amounted to $1.7 \%$ ( 3 people), followed by the women a total of $0.6 \%$ (1 person). High level shows the women of $53.9 \%$ (97 people) and men of $43.9 \%$ (79 people).

Table 12: An Analysis of the level of Emotional Intelligence (EI) College Student Council (CSC) in the dimensions of Self Management.

\begin{tabular}{lcccc}
\hline $\begin{array}{l}\text { Dimension of Self } \\
\text { Management }\end{array}$ & Men & Women & Min & S.P \\
\hline Medium High & $2.2 \%$ & $3.3 \%$ & 3.9444 & .22970 \\
High & $43.3 \%$ & $51.1 \%$ & & \\
\hline
\end{tabular}

Table 12 shows the analysis of the dimensions of self (mean $=3.9444, \mathrm{~s} . P=.22970$ ) according to group sex. The finding shows that there are differences of high and mediumhigh level by gender. Medium-high level of 3.3\% for women ( 6 persons), followed by the 
men of $2.2 \%$ ( 4 people). While the high level shows the men of $43.3 \%$ (78 persons) and women of $51.1 \%$ (92 people).

Table 13: An Analysis of the level of Emotional Intelligence (EI) College Student Council (CSC) The dimensions of Social Efficiency.

\begin{tabular}{lcccc}
\hline $\begin{array}{l}\text { Dimension of Social } \\
\text { Efficiency }\end{array}$ & Men & Women & Min & S.P \\
\hline Medium High & $0.0 \%$ & $0.6 \%$ & 3.9944 & .7454 \\
High & $45.6 \%$ & $53.9 \%$ & & \\
\hline
\end{tabular}

Table 13 shows an analysis of social efficiency dimensions (Min $=3.9944$, S.P $=.7454$ ) by gender. The findings show that there are differences in sex between medium and high levels. High simple levels only involve women as much as $0.6 \%$ ( 1 person). While the high level showed that $53.9 \%$ (97) women were followed by $45.6 \%$ (82) men.

Table 14: An Analysis of the level of Emotional Intelligence (EI) College Student Council (CSC) in the dimensions of social skills.

\begin{tabular}{lcccc}
\hline Dimension of Social Skills & Men & Women & Min & S.P \\
\hline Medium High & $7.8 \%$ & $7.8 \%$ & 3.8444 & .36344 \\
High & $37.8 \%$ & $46.7 \%$ & & \\
\hline
\end{tabular}

Table 14 shows an analysis of dimensions of social skills (Min $=3.8444$, S.P $=.36344$ ) by gender. The findings show that there is no gender difference for the medium to high men in 7.8\% (14 persons) and 7.8\% (14 persons) in women. On the other hand, for high level analysis, there were $46.7 \%$ ( 84 women), followed by $37.8 \%$ ( 68 persons).

\section{Discussion}

The findings of the study show that the level of CSC members is at high level. The findings of high moderate levels indicate no difference between genders. This is in line with the study conducted by Syakimah (2012) and Abdul (2010) who also point out that there is no significant difference between the sexes of El. It is also supported by Goleman (1998) who argues that El men and women are more equally compared to the differences. Meanwhile, for high levels, there is a difference between the sexes of men and women. The results of this study are in line with the study conducted by Abd et al (2014), Akmar (2011) and Noriah et al (2010) which state that there is a significant difference between the sexes to the level of El. In terms of CSC emotional dimensions, it is clear that there is a difference between gender for moderate and high levels of emotional dimension. The findings show that the level of CSC members in emotional dimensions is at high level. Rosenthal (1977) found that people who are able to identify the emotions of others well-mannered to gain empathy abilities are more successful in their work as well as their social lives.

For CSC members' self-management dimension, there is a difference between the high levels of gender. Self-management is an individual's ability to control and manage emotions to help other individuals achieve success. According to Syed et al (2016) self-management is the ability to control emotional reactions and serenity in order to behave honestly and with 
integrity. Individuals with high El do not let bad mood influence their behavior. Individuals behave calmly without attacking others when faced with difficult situations.

In terms of dimension of social efficiency, it is clear that it is in the middle and high stages. This shows that there is a difference between the genders of social competence among CSC members themselves. Goleman (2001) notes that social efficiency creates harmony in an organization, because the ability to understand and appreciate the emotions of others can create the harmony and comfort of fellow members in the organization and can help and improve the satisfaction and performance of the work.

For the dimensions of social skills, it is clear that it is in moderation high and high. Pasanen (2000) through his study found that the social skills aspect could be the most effective predictor of the behavior of citizen organizations, especially in relation to one's loyalty to the field involved and the organization in which they served. This skill, if used properly, can create harmonious relationships between CSC members and students who can create fun and satisfaction. These social skills can also produce excellent CSC members.

$\mathrm{El}$ is an aspect in which a CSC member can and should be developed and trained. It is not a gift naturally acquired through genetics. Significant increase in El level after interventions carried out among CSC members showed that El could have a positive impact in an environment such as creating a sense of collaboration, high motivation, productivity improvement and more. El among CSC members is very important as it can determine organizational effectiveness, teamwork, engagement in activities, quality of service and relationships with students in residential colleges.

The findings of the study showed that there was a difference between the gender and the CSC member level after intervention. According to Goleman (1998), individuals with high El have motivation in pursuing a goal to achieve. Therefore, CSC members should always strive to achieve and ensure their goals are met. If the desired goal is achieved with the support of these parties, it is possible to give satisfaction to the CSC members in the courses, activities or fields they are involved in.

The results obtained after the intervention by using SSMEI showed that there was an increase in the level of CSC members. This finding is in line with the study conducted by Azromihana (2004) that there are differences in gender in terms of self-control components (self-management) and this shows that El shows the improvement that goes along with the youth's own development.

In terms of social efficiency also, it is clear that there is a difference between the genders of CSC members in each college. The ability to recognize the emotions of others can help in building a positive and effective relationship. Empathy is an ability to feel everything that other people are feeling. CSC members need to have a sense of empathy that is to feel everything else around them to feel and feel the emotions of others like their own experiences. This does not mean that CSC members need to agree on the whole, but it means that CSC can and can understand the feelings of others, can communicate effectively and care about it.

The findings of the study also showed that there was an increase in the level of CSC members in the dimensions of social skills after intervention. According to Syed et al (2016), social skills are the ability to communicate clearly and convincingly. This communication can be seen in leaders where they can influence others without giving negative impact to others. However, this does not mean that rational arguments can be neglected but understand how to use emotions to persuade and communicate. 


\section{Conclusion}

Most of the studies done clearly show that when El high, one will be more involved and successful in all areas involved. This is in line with Goleman's (1995) opinion that 80 percent of the individual's success is determined by El compared to IQ which contributes only 20 percent. Yet all this depends and lies directly on the determination and willingness of a person in the full involvement of whatever field they belong to either in association or in the career they have chosen. In addition, Goleman (1998) in his theoretical framework also thinks that one's excellence in his organization environment depends on his ability to use the emotional aspects of his El.

The results from the findings as a whole show that the level of El among the members of CSC UPSI is at high and medium level. The findings also show that there is a difference between gender for all dimensions in El before and after intervention using SSMEI. Studies have found that those with high El have been able to effectively communicate ideas, information and demands to others. It is therefore evident that $\mathrm{El}$ is not genetic or natural borne but can be enhanced through more structured engagement and exercises.

\section{Acknowledgement}

This study is sponsored by Sultan Idris Education Universiti under Education Based Research Grant with reference code 2018-0033-107-01.

\section{Corresponding Author}

Name : $\quad$ Associate Professor Dr Syed Sofian Syed Salim

Affiliation: Sultan Idris Education University

Country: Malaysia

Email ID : $\quad$ sofian@fpm.upsi.edu.my

Address: $\quad$ Faculty of Education and Human Development, Sultan Idris Education University 35900 Tanjong Malim, Perak

\section{References}

Abd, A. A. S., Omar, H. M. B. \& Eftah, M. (2014). Evaluating Emotional Intelligence and Achievement Motivation Leavers Excellent PMR Leavers Mathematics by gender. Proceedings of the International Conference Teaching and Learning (ICTL 2014), Sultan Idris Education University, Perak, Malaysia.

Abdul, G. (2010). Emotional Intelligence (EI) In Form Six Students in Urban and Rural Areas. Perak: Sultan Idris Education University.

Akmar, A. H. (2011). The Influence of Emotional Intelligence and Personality towards Secondary School Academic Achievement. Perak: Universiti Pendidikan Sultan Idris.

Azromihana, A. (2004). The level of Emotional Intelligence among Teenagers in Kuala Lumpur. Selangor:National University of Malaysia.

Goleman, D. (1998). Working With Emotional Intelligence. New York: Bantam Books.

Goleman, D. (2001). Emotional intelligence: Issues in paradigm building. In C. Cherniss and D. Goleman (Ed's.), The Emotionally Intelligence Workplace. San Francisco: JosseyBass.

Ilyana, A. H. (2009). Emotional Intelligence (EQ) the Prefect of schools in urban and rural areas. Perak: Sultan Idris Education University. 
Niehoff, B. P. \& Moorman, R. H. (1993). Justice as a Mediator of the Relationship between Methods of Monitoring and Organizational Citizenship Behavior. Academy of Management Journal. 36(3), pp. 527-556.

Noriah, M. I., Shaharuddin, A., Kadderi, M. D. \& Roslina, T. A. (2010). Emotional Intelligence As A Factor For Academic Achievement IPTA: The Implication on Marketability. Selangor: University of Teknology, Malaysia.

Pasanen, S. E. (2000). Emotional Intelligence, Conscientiousness and Integrity as Predictors of Organizational Citizenship Behavior. Los Angeles: University of California.

Rosenthal, R. (1977). The PONS Test: Measuring sensitivity to nonverbal cues. In McReynolds, P. (ed). Advances in psychological assessment. San Francisco: JosseyBass.

Syakimah, M. (2012). The level of emotional intelligence among secondary school students. Perak: Sultan Idris Education University.

Syed, S. S. S., Mohammad, A. S. M. A., Muhammad, B. M. \& Mohd, H. M. Y. (2016). Construction of Sofian Emotional Intelligence Inventory (IKESOFI) based on the Model of New Mixed Emotional Intelligence Goleman (MKEC (b) G). Perak: Sultan Idris Education University. 